\title{
ESTUDO DE CASO SOBRE FLUXO DE CAIXA COMO FERRAMENTA DE CONTROLE PARA EMPRESA DO SETOR DE COSMÉTICOS EM TANGARÁ DA SERRA - MT
}

\author{
Cristiane Sanini ${ }^{1}$ \\ Maykon J.B. de Camargo ${ }^{2}$
}

\section{RESUMO}

O presente estudo teve por objetivo verificar a relevância do uso da demonstração de fluxo de caixa pelo método direto como ferramenta de controle. Para isto foi utilizado o modelo do Comitê de Pronunciamentos Contábeis (CPC-03) de fluxo de caixa que permite a visualização antecipada dos excessos ou insuficiências a curto prazo, criando a possibilidade de simulações, que auxiliam o gestor a planejar as ações que serão implementadas em seu negócio. Trata-se de pesquisa bibliográfica de natureza descritiva, com abordagem quantitativa. As estratégias utilizadas foram o estudo de caso e documental onde levantou-se documentação para análise referente aos meses de julho de 2012 a junho de 2013. Tal estratégia possibilitou ao gestor da organização estimar as atividades realizadas de modo a facilitar a análise de qual será a melhor forma de investir os recursos financeiros disponíveis bem como, constatar eventuais necessidades de captação de recursos de terceiros. O presente estudo foi direcionado para a empresa familiar do ramo de cosméticos.

Palavras chave: Ferramenta de Controle - Fluxo de caixa - Método direto - Empresa familiar.

\section{INTRODUÇÃO}

Para Maximiano (2000), apesar de todos os empreendimentos oferecerem riscos é possível prevenir-se contra eles, utilizando ferramentas operacionais que possam amenizar e auxiliar o gestor na tomada de decisão. Planejar é a mais básica das funções gerenciais e a capacidade de desempenho dessa função esta diretamente ligada ao sucesso das operações da empresa. De acordo com Silva (2005) a empresa organizada precisa de outras formas de relatórios que decorrem das necessidades gerenciais para auxiliar no processo decisório e não somente as demonstrações financeiras.

Com a criação da Lei 11.638, em 28 de Dezembro de 2007, a Contabilidade brasileira passou a ser convertida nos moldes do padrão internacional, isto é, das IFRS - International Financial Reporting Standards e, somada ao intenso processo de informatização do sistema de fiscalização, tornou a Contabilidade, mais do que nunca, peça chave para a sobrevivência das empresas. O Fluxo de Caixa pode ser demonstrado de diversas maneiras, assumindo várias faces, desde que cumpra a função básica de fornecer informações acerca do fluxo de pagamentos e recebimentos num dado período. Cabe ressaltar, que apenas para fins

\footnotetext{
${ }^{1}$ Acadêmica do Curso de Ciências Contábeis da UNEMAT - Campus de Tangará da Serra, e-mail : cristiane_sanini@hotmail.com

${ }^{2}$ Bacharel em Administração de empresas, Professor do Departamento de Administração da UNEMAT Campus Universitário de Tangará da Serra 
Estudo de caso sobre fluxo de caixa como ferramenta de controle para empresa do setor de cosméticos em Tangará da Serra - MT

Cristiane Sanini

Maykon J.B. de Camargo

operacionais pode-se formatar o fluxo de caixa conforme a nossa conveniência, visando atender as necessidades informacionais do usuário, porém, para fins legais, de acordo a Lei n. ${ }^{\circ}$ 11.638, de 2007, a elaboração da demonstração do fluxo de caixa torna-se obrigatória, mas o seu formato de apresentação ainda é passível de escolha, onde em seu art.176, estabelece que todas as empresas de capital aberto e fechado com patrimônio liquido na data do balanço inferior a $\mathrm{R} \$ 3.600 .000,00$ (três milhões e seiscentos mil), não será obrigada a elaboração da Demonstração do Fluxo de Caixa.

A presente pesquisa aborda a necessidade do gestor acompanhar o desempenho da empresa através de sua capacidade de geração de caixa, neste contexto se destaca o uso fluxo de caixa como instrumento que possibilita o planejamento, uma vez que o caixa determina a sobrevivência da empresa, e é através dele que saberá se possui liquidez para saudar seus compromissos, ou se necessitará fazer financiamentos, sendo que o planejamento financeiro evitará surpresas e criará planos alternativos caso ocorram imprevistos.

Por meio do planejamento financeiro as metas estabelecidas para o crescimento da empresa atingem resultados satisfatórios. Segundo afirma Almeida (2001), o planejamento financeiro torna-se um instrumento indispensável para a estratégia empresarial fornecendo um referencial técnico para os gestores tomarem decisões que acarretam no crescimento da empresa.

O empreendimento de sucesso visa contemplar todas as áreas da empresa, o planejamento deve ser entendido e gerido com competência e seriedade segundo Gitman (2002, p. 589) "o planejamento financeiro é um aspecto importante para o funcionamento e sustentação da empresa, pois fornece roteiros para dirigir, coordenar e controlar suas ações na obtenção de seus objetivos”. Para Teló (2001, p. 20) “o planejamento financeiro estabelece o modo pelo qual os objetivos financeiros podem ser alcançados".

Diante deste contexto, tendo em vista a importância do planejamento financeiro para as empresas perante o papel que assumem na sociedade onde possibilita a comercialização de produtos para satisfazer as necessidades dos consumidores, nesse processo, a empresa gera lucro, cria riqueza, essa é distribuída não só para proprietários, como também para colaboradores, fornecedores, Estado e a sociedade em geral, com isso o objetivo geral desta pesquisa foi de analisar o fluxo de caixa como ferramenta de controle para empresa de cosméticos em Tangará da Serra - MT, , portanto, o problema desta pesquisa resume-se em, como se dá o uso do método direto do fluxo de caixa na organização analisada? 
Estudo de caso sobre fluxo de caixa como ferramenta de controle para empresa do setor de cosméticos em Tangará da Serra - MT

Cristiane Sanini

Maykon J.B. de Camargo

Para alcançar o objetivo geral, têm-se os seguintes objetivos específicos: (1) Apresentar os aspectos conceituais quanto ao planejamento financeiro, visando o fluxo de caixa pelo método direto; (2) Analisar o controle do fluxo de caixa pelo método direto; (3) Demonstrar os resultados do método direto através de planilhas e/ou tabelas e os benefícios que pode trazer para a empresa.

O estudo é composto de introdução que compõe breve apresentação do trabalho realizado, o referencial teórico contempla assuntos relacionados com a Demonstração do Fluxo de Caixa, onde se identificam conceitos técnicos de autores consagrados que serviram de orientação para o desenvolvimento deste trabalho, a metodologia compreende os procedimentos utilizados para o seu desenvolvimento na análise e interpretação dos dados, aborda a descrição da empresa e a interpretação dos dados do estudo de caso, por fim, expõem-se as conclusões e também se os objetivos, inicialmente propostos, foram alcançados, além de limitações do estudo e sugestões para novos trabalhos.

\section{REFERENCIAL TEÓRICO}

\subsection{A Administração e suas Tendências}

Pode-se conceituar, então, planejamento financeiro como aquele planejamento que, centrado na interação da empresa com seu ambiente externo, focalizando as ameaças, oportunidades e seus reflexos na própria empresa, evidenciando seus pontos fortes e fracos, definindo as diretrizes estratégicas, segundo menciona Maximiano (2000).

Para Gitman (2002), planejamento pode ser definido como um processo gerencial que possibilita ao empresário estabelecer o rumo a ser seguido pela empresa, com vistas a obter um nível de otimização na relação da empresa com seu ambiente. Um plano bem elaborado representa um salto qualitativo para quem busca um norte para seus negócios e sofre com a natural dificuldade em organizar ideias e objetivos de forma clara. Com um planejamento bem delineado, as empresas obtêm ferramentas necessárias para uma melhor gestão dos recursos disponíveis e conhecimento mais amplo de seu mercado de atuação. De acordo com Hoji (2010), enfatiza que o planejamento consiste de um processo de análise das oportunidades e ameaças (ambiente externo) e dos pontos fortes e fracos (ambiente interno) da organização, com vistas a definir diretrizes estratégicas para assegurar o cumprimento da missão da empresa. Desse modo Hoji (2010), com essas informações em mãos, se elabora um plano de ação para atingir suas metas, sejam elas, aumentar o faturamento, lançar ou reformular um produto, contratar um negócio ou abrir uma nova unidade. 
Estudo de caso sobre fluxo de caixa como ferramenta de controle para empresa do setor de cosméticos em Tangará da Serra - MT

\subsection{Planejamento Estratégico}

Para Stoner e Freeman (1995), o planejamento pode ser visto como uma função inicial da administração. Considerando o planejamento como ferramenta que impulsiona as ações de organizar, liderar e controlar.

O uso eficiente de um plano financeiro é resumido por Cherry (1977) como o estreitamente associado com a aquisição eficiente de fundos e seu uso adequado. $\mathrm{O}$ planejamento financeiro ajuda a garantir as disponibilidades de fundos suficientes quando necessários, informa com antecedência as necessidades de maneira que as negociações sejam eficientes e aumentem as possibilidades de rendimento.

Para Stoner e Freeman (1995), o planejamento pode ser condensado em quatro passos básicos e adaptado a todas as suas atividades e aos níveis organizacionais, conforme o roteiro a seguir no quadro 01 .

Quadro 1 - Os quatro passos básicos do planejamento

\begin{tabular}{|l|}
\hline PASSO 1: estabelecimento dos objetivos \\
\hline PASSO 2: definição da situação atual \\
\hline PASSO 3: determinação das facilidades e das barreiras \\
\hline PASSO 4: preparo de um conjunto de medidas \\
\hline PASSO 5: definição de metas \\
\hline
\end{tabular}

Fonte: Stoner e Freeman (1995, p. 91)

Passo 1: Estabelecer um objetivo ou um conjunto de objetivos. O planejamento tem início com a definição sobre o que a organização ou uma subunidade deseja alcançar. A identificação de prioridades e a determinação de seus fins possibilitam uma utilização eficaz dos recursos.

Passo 2: Definir a situação atual, ou seja, analisar até que ponto a organização está afastada de seus objetivos e com que recursos ela pode contar para atingir seus objetivos. Essas informações são fornecidas por intermédio dos canais de comunicação dentro da organização e entre suas subunidades.

Passo 3: Identificar que fatores internos e externos podem ajudar ou criar problemas para a organização no alcance dos seus objetivos.

Passo 4: Elaborar um plano ou um conjunto de ações para atingir o(s) objetivo(s). Envolve a determinação de diversas alternativas e a escolha da mais apropriada para se atingir os objetivos propostos.

Passo 5: Este último passo não é necessário se o planejador, após o exame da situação atual, previr que o plano que já está sendo executado conduzirá a organização ou a 
Estudo de caso sobre fluxo de caixa como ferramenta de controle para empresa do setor de cosméticos em

Tangará da Serra - MT

Cristiane Sanini

Maykon J.B. de Camargo

subunidade à consecução de seu objetivo.

Todavia, faz-se o planejamento se as condições atuais não estejam atingindo os objetivos e satisfazendo as expectativas, sendo necessário elaborar outro plano.

\subsection{Objetivos do planejamento}

Os objetivos do planejamento podem ser descritos como o estado futuro desejado e os caminhos para atingi-lo. Segundo Maximiano (2000), objetivos são resultados desejados, que orientam o intelecto e a ação. São fins, propósitos, intenções ou estados futuros que as pessoas e as organizações pretendem alcançar, por meio da aplicação de esforços e recursos. A maioria dos erros ocorre porque os envolvidos no processo concentram apenas na formulação da estratégia e falham na prática das mesmas.

Segundo Certo (1995), o fracasso provavelmente ocorre quando uma estratégia é mal formulada e mal implantada. Quando isto ocorre, os administradores envolvidos têm grandes dificuldades de voltarem para o caminho certo, pois, se recomeçarem a estratégia, provavelmente ocorrerá falha, e se reformularem a estratégia, o fracasso torna-se um risco. Certo (1995), refere ainda que deve ficar claro, que a implantação da estratégia é tão importante quanto a sua formulação. O objetivo do planejamento estratégico é estabelecer quais serão os caminhos a ser percorridos para se atingir a situação desejada conforme cita Maximiano (2000).

\subsection{Organizações Familiares}

Cabe aqui definir o conceito de empresa familiar. Para Bernhoeft (1989), uma empresa familiar é aquela que tem sua origem e sua história vinculadas a uma família, ou ainda, aquela que mantém membros da família na administração do negócio.

Para Donnelley (1976), é a empresa que tenha sua origem ligada a uma família e em que as ligações familiares ainda exercem influência sobre as diretrizes empresariais. As empresas familiares são típicas organizações que carregam, desde a sua concepção características próprias que as distingue das demais. A definição de empresa encontrada em Maximiano (2000, p.48), apoiado em Fayol, a seguinte conceituação:

"Fayol considera a empresa como um sistema racional de regras e de autoridade, que
justifica sua existência à medida que atende ao objetivo primário de fornecer valor,
na forma de bens e serviços, a seus consumidores".

O conceito de empresa familiar defendido por Donnelley (1967), Lodi (1998) e Ricca (1998) é aquele em que a família controla o negócio há pelo menos duas gerações. Nesta 
Estudo de caso sobre fluxo de caixa como ferramenta de controle para empresa do setor de cosméticos em

Tangará da Serra - MT

Cristiane Sanini

Maykon J.B. de Camargo

situação, existe uma influência recíproca da política geral da firma e dos interesses e objetivos familiares. Já o conceito de Leone (1991), caracteriza a empresa familiar pela observação dos seguintes aspectos:

a) iniciada por um membro da família;

b) membros da família participantes da propriedade e/ou da direção;

c) valores institucionais se identificando com um sobrenome de família ou com a figura do fundador;

d) sucessão ligada ao fator hereditário.

Nesse sentido, esse conceito congrega três vertentes. A primeira é a propriedade, a segunda é a gestão e a terceira é a sucessão. Lodi (1998), por sua vez, diz que todas as empresas, a rigor, tiveram um fundador ou um pequeno grupo de fundadores, que eram seus donos. As ações ou cotas de empresa seriam provavelmente herdadas por seus filhos. Praticamente, todas as empresas, portanto, foram familiares na origem.

O mais importante valor da empresa é a família, identificada e representada em temas formais e nas tradições informais. Toda decisão ou atitude tomada por um membro da família é referida ou interpretada como um reflexo da reputação e da cultura da companhia, independente de quaisquer laços formais com a administração" (RICCA, 1998, p.09).

Para Almeida (2001), as empresas familiares são eficientes no seu dia a dia, mas ineficazes nas decisões que envolvem o caixa da empresa. Assim o autor sugere que a técnica administrativa apropriada para solucionar este problema é o planejamento financeiro. Ainda, com o aumento da competitividade as empresas familiares concorrem, na maioria das vezes, com grandes empresas, que, por sua vez, conhecem os benefícios do planejamento financeiro e o utilizam como ferramenta fundamental para o desenvolvimento da empresa.

\subsection{Administração financeira}

Segundo Chiavenato (2006, p.231), finanças significa a ação de prover os meios de pagamento. Assim, as finanças incluem o planejamento financeiro, a estimativa de entradas e saídas de caixa, o levantamento de fundos, o emprego e a distribuição desses fundos e o seu controle financeiro para confrontar o que foi realmente executado com os planos originais. $\mathrm{O}$ termo administração financeira vai mais além. Além de providenciar para que as contas sejam pagas, torna-se necessário criar os meios para perpetuar a empresa e alcançar os lucros previstos pelos proprietários ou acionistas.

De acordo com Gitman (2002), a maioria das decisões empresariais são medidas em termos financeiros, logo, o administrador financeiro desempenha um papel crucial na 
Estudo de caso sobre fluxo de caixa como ferramenta de controle para empresa do setor de cosméticos em

Tangará da Serra - MT

Cristiane Sanini

Maykon J.B. de Camargo

operação da empresa. As pessoas de todas as áreas de responsabilidade da empresa necessitam interagir com o pessoal de finanças para realizar seu trabalho. Consequentemente, o pessoal de finanças, para fazer previsões úteis e tomar decisões, precisa ter a disposição e a capacidade de conversar com todos, dentro da empresa.

\begin{abstract}
"As métricas são indispensáveis para se analisar o desempenho e os resultados obtidos. O que não se pode medir não se pode administrar. Um índice é o quociente resultante de uma equação. Um índice financeiro corresponde à comparação de valores monetários absolutos e que proporciona um dado relativo entre eles". Chiavenato (2006, p. 85).
\end{abstract}

De acordo com Gitman (2002, p. 102), finanças pode ser definida como "a arte e a ciência de administrar fundos. Praticamente, todos os indivíduos e organizações obtêm receitas ou levantam fundos, gastam ou investem. Finanças ocupa-se do processo, instituições, mercados e instrumentos envolvidos na transferência de fundos entre pessoas, empresas e governos".

\title{
2.6 Fluxo de Caixa
}

Para Zdanowicz (1998, p.33), “o fluxo de caixa é o instrumento que permite demonstrar as operações financeiras que são realizadas pela empresa", o que possibilita melhores análises e decisões quanto à aplicação dos recursos financeiros que a empresa dispõe.

Para Zdanowicz (1998), o Fluxo de Caixa tem por objetivo fundamental levantar todas as necessidades da organização, para que possa cumprir com todas as obrigações nos prazos certos, alcançando resultados positivos considerando os desembolsos necessários para o seu funcionamento.

O fluxo de caixa torna-se ferramenta para o gerenciamento financeiro, a fim de tornar mais sólido as decisões a serem tomadas. O controle pode ser feito de curto prazo, onde pode ser definidas as despesas que a empresa terá ou no mínimo poderá ter para o próximo período, afim de não precisar entrar em cheque especial no banco, ou decisões paralelas, como por exemplo, factoring, empréstimos, entre outros.

Para as micro e pequenas empresas, geralmente o que acontece é que os empresários acabam não se programando para o próximo período, então, ao ver o caixa com dinheiro, não se atenta para a duplicata que vencerá nos próximos dias, e acaba por, embolsar e gastar o dinheiro, enfatizado por Drucker (1995). Para Hoji (2010, p.79), “o Fluxo de Caixa é um esquema que representa as entradas e saídas de caixa ao longo do tempo. Em um Fluxo de caixa, deve existir pelo menos uma saída e pelo menos uma entrada (ou vice-versa)". 


\subsubsection{Método direto}

O método direto pode ser assim detalhado:

"O Fluxo de Caixa pelo método direto é também denominado Fluxo de Caixa no Sentido Restrito. Muitos se referem a ele como o "verdadeiro Fluxo de Caixa", porque, (...) nele são demonstrados todos os recebimentos e pagamentos que efetivamente concorreram para a variação das disponibilidades no período". Marion (2003, p.431).

No método direto, nas atividades operacionais, são apresentados primeiro os itens referentes às entradas depois às saídas. Primeiramente apresenta-se o valor da receita de vendas de mercadorias e serviços que geraram caixa, depois se subtraem os pagamentos efetuados a fornecedores, salários e encargos sociais, impostos e outras despesas, em seguida são adicionados os dividendos recebidos, os recebimentos de seguros e outros.

Atividade Operacional: para Campos Filho (1999), este grupo deve conter os recebimentos e pagamentos relacionados à atividade operacional principal da empresa geradoras de receita da entidade - (aquisição de mercadoria, produção, financiamento de clientes, pagamento de fornecedores, etc.) e que na maioria das vezes estão ligados às receitas e despesas que compõem a demonstração do resultado. Podem ser agrupadas da seguinte forma:

Ingressos de Recursos ou Entradas de Recursos:

a) recebimentos, à vista, de mercadorias, serviços e produtos, bem como do recebimento das duplicatas das vendas a prazo;

b) recebimentos de juros sobre empréstimos concedidos e sobre aplicações financeiras em outras entidades, bem como dos dividendos de participações em outras sociedades;

c) recebimentos que não se originem de transações definidas como atividades de investimento ou financiamento.

Saídas de Recursos ou Alocações de Recursos:

a) pagamentos, à vista, a fornecedores de bens objeto de sua atividade fim, bem como do pagamento dos fornecedores de compras originalmente a prazo;

b) pagamento de despesas da atividade fim da empresa, tais como, salários, aluguéis, com vendas, financeiras (juros), etc;

c) pagamentos de impostos e contribuições aos diversos governos, bem como aos pagamentos acessórios, tais como multas; etc.

Atividade de investimento: relaciona-se normalmente com operações envolvendo os ativos de longo prazo que a empresa utiliza para produzir bens e serviços, incluindo a 
Estudo de caso sobre fluxo de caixa como ferramenta de controle para empresa do setor de cosméticos em Tangará da Serra - MT

Cristiane Sanini

Maykon J.B. de Camargo

aquisição e alienação de ativo permanente investimento, imobilizado, bem como a concessão de empréstimos, conforme Campos Filho (1999).

Ingressos de Recursos ou Entradas de Recursos:

a) recebimento do principal dos empréstimos concedidos (os juros recebidos destes empréstimos são classificados como atividade operacional);

b) recebimento pela venda de participações em outras empresas;

c) recebimento pela venda de ativo permanente imobilizado.

Saídas de Recursos ou Alocações de Recursos:

a) concessão (desembolso) de empréstimos a outras empresas

b) aquisição (pagamento) de títulos patrimoniais de outras empresas;

c) aquisição (pagamento) de ativo permanente imobilizado.

Atividade de financiamento: este grupo contempla os pagamentos e recebimentos relacionados às atividades de captação de recursos junto à terceiros ou acionistas para financiamento dos investimentos e operações da em presa, que resultam em mudanças no tamanho e na composição do capital próprio.

Segundo Campos Filho (1999). Tais como, ingressos de Recursos ou Entradas de Recursos e saídas de Recursos ou Alocações de Recursos:

A seguir um modelo de Demonstração de Fluxo de Caixa extraído do CPC 03, mostrado na Tabela 01 .

Tabela 01: Demonstração dos Fluxos de Caixa pelo Método Direto

\begin{tabular}{|c|c|}
\hline Demonstração dos Fluxos de Caixa pelo Método Direto & $\begin{array}{c}\text { Totais } \\
\text { (R\$) }\end{array}$ \\
\hline \multicolumn{2}{|l|}{ Fluxos de caixa das atividades operacionais } \\
\hline \multicolumn{2}{|l|}{ Recebimentos de clientes } \\
\hline \multicolumn{2}{|l|}{ Pagamentos a fornecedores e empregados } \\
\hline \multicolumn{2}{|l|}{ Caixa gerado pelas operações } \\
\hline \multicolumn{2}{|l|}{ Juros pagos } \\
\hline \multicolumn{2}{|l|}{ Imposto de renda e contribuição social pagos } \\
\hline \multicolumn{2}{|l|}{ Imposto de renda na fonte sobre dividendos recebidos } \\
\hline \multicolumn{2}{|l|}{ Caixa líquido proveniente das atividades operacionais } \\
\hline \multicolumn{2}{|l|}{ Fluxos de caixa das atividades de investimento } \\
\hline \multicolumn{2}{|l|}{ Aquisição da controlada $X$ líquido do caixa incluído na aquisição } \\
\hline \multicolumn{2}{|l|}{ Compra de ativo imobilizado } \\
\hline \multicolumn{2}{|l|}{ Recebido pela venda de equipamento } \\
\hline \multicolumn{2}{|l|}{ Juros recebidos } \\
\hline \multicolumn{2}{|l|}{ Dividendos recebidos } \\
\hline Caixa líquido usado nas atividades de investimento & \\
\hline
\end{tabular}


Estudo de caso sobre fluxo de caixa como ferramenta de controle para empresa do setor de cosméticos em Tangará da Serra - MT

Cristiane Sanini

Maykon J.B. de Camargo

Recebido pela emissão de ações

Recebido por empréstimo a logo prazo

Pagamento de passivo por arrendamento

Dividendos pagos*

Caixa líquido usado nas atividades de financiamento

Aumento líquido de caixa e equivalentes de caixa

Caixa e equivalentes de caixa no início do período

\section{Caixa e equivalentes de caixa ao fim do período}

Fonte: Comitê de Pronunciamentos Contábeis (CPC - 03)

(*) Esse valor também pode ser apresentado no fluxo de caixa das atividades operacionais.

Para Ribeiro (2005, p.304), “[...] pelo método direto os Recursos Derivados das operações são indicados a partir dos recebimentos e pagamentos decorrentes das operações normais efetuados durante o período." Ressalte-se ainda, que o método direto é de fácil entendimento por não informar as entradas e saídas de recursos pelas variações nas contas operacionais ativas e passivas.

\subsection{Características básicas para um informativo de Fluxo de Caixa}

A montagem de um demonstrativo gerencial que proporcione informações claras tem como características básicas na proposta de Kassai (1997) para organizações familiares:

a) Simplicidade: as informações devem ser de entendimento intuitivo, não sendo necessário o conhecimento dos princípios e convenções contábeis que regem a contabilidade;

b) Facilidade de obtenção: as informações devem ser fáceis de levantar, sem necessidade de registros históricos ou complexos;

c) Relevância: Preocupação inicial com as informações relevantes, desconsiderando-se os valores menores

d) Atualidade: Propõe-se um modelo de informação voltada para os fatos e eventos presentes e futuros, através da utilização de modelos prospectivos e orçamentos;

e) Funcionalidades e Simulações: um instrumento entendido e utilizado de maneira simples, fácil e que permita simular o crescimento ou a queda das vendas, aumento ou diminuição dos custos / despesas e outras variáveis que possam auxiliar na tomada de decisões;

f) Facilidade de manipulação das informações: a popularização dos microcomputadores possibilitou o desenvolvimento de modelos de softwares conhecidos e de fácil manipulação. 
Estudo de caso sobre fluxo de caixa como ferramenta de controle para empresa do setor de cosméticos em Tangará da Serra - MT

Cristiane Sanini

Maykon J.B. de Camargo

Portanto, ao utilizar-se do método direto verifica-se que esse modelo possui características que interpretam mais facilmente os dados uma vez que demonstra os principais fluxos de entrada e de saída de caixa em linhas separadas, permitindo que o usuário faça a confrontação.

\subsection{Fatores que afetam o caixa}

De acordo com Dalbello (1999), a projeção mensal do fluxo de caixa ajuda a identificar e eliminar insuficiência de caixa e a visualização e aplicação das sobras do mesmo. Se o fluxo de caixa apresentar-se negativo, o gestor financeiro deve alterar seus planos para conseguir mais dinheiro. Por outro lado, um fluxo de caixa com grandes sobras de recursos pode indicar que se pediu dinheiro emprestado além do necessário ou que não foram investidos os excedentes de caixa. O objetivo é obter um equilíbrio entre as entradas e saídas de caixa e mantê-lo no mínimo, somente para suprir as necessidades da empresa.

Dentre as movimentações das atividades representadas na demonstração do fluxo de caixa, algumas são apontadas por Marion (2003) como sendo as principais transações que afetam o caixa, divididas em 2 (dois) grupos distintos: as transações que aumentam e as que diminuem o caixa e os seus equivalentes.

Segundo Marion (2003) as transações que aumentam o caixa, são: integralização do capital pelos sócios ou acionistas em dinheiro, empréstimos bancários, financiamentos, venda de itens do ativo permanente, outras entradas tais como juros recebidos, dividendos recebidos de outras empresas, indenizações de seguros recebidas. Todas essas transações representam quando ocorre entrada de caixa e equivalentes. Ainda de acordo com o autor apresenta-se as transações que não afetam o caixa: depreciação, amortização e exaustão, provisão para devedores duvidosos, reavaliação, acréscimo (ou diminuições) de itens de investimentos pelo método de equivalência patrimonial. Essas transações não representam desembolso de caixa, portanto, não afetam o Caixa.

\subsection{Benefícios do uso do fluxo de Caixa pelo Método Direto}

Conforme o Comitê de Pronunciamentos Contábeis (CPC-03) as informações contidas na Demonstração do Fluxo de Caixa, quando são utilizadas conjuntamente com as informações contidas nas outras demonstrações contábeis, poderão auxiliar aos usuários na avaliação da capacidade da empresa de gerar fluxos de caixa líquidos positivos decorrentes de 
Estudo de caso sobre fluxo de caixa como ferramenta de controle para empresa do setor de cosméticos em Tangará da Serra - MT

Cristiane Sanini

Maykon J.B. de Camargo

suas atividades, visando atender às suas obrigações bem como pagar aos dividendos. Alguns benefícios das informações sobre os Fluxos de Caixa pelo método direto são:

a) o fluxo de caixa pelo método direto é útil para avaliar a capacidade da empresa produzir recursos de caixa e valores equivalentes e habilitar os usuários a desenvolver modelos para avaliar e comparar o valor presente e futuro de caixa de diferentes períodos;

b) possibilidade de uso das informações históricas sobre o fluxo de caixa pelo método direto como indicador da importância, época e certeza de futuros fluxos de caixa;

c) avaliar possíveis alternativas de investimentos com as sobras de caixa e certificar que os excessos momentâneos de caixa estão sendo devidamente aplicados;

d) avaliar e controlar ao longo do tempo as decisões importantes que são tomadas na empresa, com reflexo monetário;

e) avaliar as situações presente e futura do caixa na empresa, posicionando-a para que não chegue a situações de iliquidez.

f) criar condições favoráveis para que a classificação dos recebimentos e pagamentos siga critérios técnicos e não fiscais;

g) permite que a cultura de administrar pelo caixa seja introduzida mais rapidamente nas empresas; e

h) as informações de caixa podem estar disponíveis diariamente.

Para utilizar-se desses benefícios a organização deve ter em mãos, discriminado em seus montantes, as contas de recebimentos e pagamentos das atividades operacionais, de investimento e de financiamento, tendo como principal benefício permitir a geração de informações com base em critérios técnicos livre de qualquer interferência da legislação fiscal.

\section{METODOLOGIA}

A pesquisa caracterizou-se como descritiva, com abordagem quantitativa, segundo Gil (1995) descritiva por descrever características de determinada população ou fenômeno ou, o estabelecimento de relações entre as variáveis, observando e descrevendo os fatos sem manipulá-los. Para Beuren e Raupp (2009, p.81), "uma das características mais significativas das pesquisas descritivas está na utilização de técnicas padronizadas de coleta de dados”, visto que o pesquisador pode observar os fatos, analisá-los, classificá-los e interpretá-los sem que o mesmo interferisse neles. Também foi utilizada uma pesquisa bibliográfica, objetivando a 
Estudo de caso sobre fluxo de caixa como ferramenta de controle para empresa do setor de cosméticos em Tangará da Serra - MT

Cristiane Sanini

Maykon J.B. de Camargo

construção de um referencial teórico, com enfoque no fluxo de caixa pelo método direto de informações geradas na organização.

Quanto aos procedimentos, foi utilizada a estratégia de estudo de caso, que caracteriza principalmente pelo estudo de um único fato, na qual o pesquisador deseja aprofundar seu conhecimento (Beuren e Raupp, 2009), e documental, que segundo Vergara (2006) é realizada em documentos conservados no interior de órgãos públicos e privados de qualquer natureza, ou com pessoas, como registros, anais, regulamentos circulares, ofícios entre outros documentos internos.

Também foi utilizado o instrumento por meio de cenários, que identificou o uso do método direto do fluxo de caixa, como ferramenta de gestão, realizado através do fornecimento de documentos comprobatórios cedidos pela contabilidade da mesma, tais como: Demonstração do Resultado do Exercício, Livro Diário, Livro Razão, Livro Registro de Entradas, Balanço Social entre outros, que na concepção de Godet (1997) visa organizar o exercício prospectivo, objetivando a definição de estratégias e clarificando os meios de execução, servindo como ferramenta de apoio para tomada de decisões. Foram coletadas informações e dados contábeis referente aos meses de julho a dezembro de 2012 e janeiro a junho de 2013, por meio do escritório contábil que presta serviço à empresa desde a sua constituição,

De acordo com Roesch (2005) a validade da pesquisa dependerá da habilidade, competência e seriedade do pesquisador. Os dados da pesquisa foram tratados qualitativamente com o interesse de compreender o fluxo de caixa pelo método direto utilizado na empresa familiar em questão, dados esses, organizados em planilhas e tabelas de forma a permitir a visualização dos ingressos e desembolsos dos recursos financeiros.

\section{RESULTADOS E DISCUSSÕES}

\subsection{Análise dos Resultados}

A Demonstração do Fluxo de Caixa (DFC) passou a ser obrigatória no Brasil, a partir da Lei $n^{\circ} 11.638 / 07$, para todas as sociedades anônimas e demais empresas consideradas de grande porte. Segundo o pronunciamento técnico CPC 03, em seu item 11 "a demonstração dos fluxos de caixa deve apresentar os fluxos de caixa por período classificados por atividades operacionais, de investimento e de financiamento".

De acordo com Iudícibus (2010, p.565), o “objetivo primário da Demonstração dos Fluxos de Caixa é prover informações relevantes sobre os pagamentos e recebimentos, em 
Estudo de caso sobre fluxo de caixa como ferramenta de controle para empresa do setor de cosméticos em Tangará da Serra - MT

Cristiane Sanini

Maykon J.B. de Camargo

dinheiro, de uma empresa, ocorridos durante um determinado período", contribuindo assim para identificar as condições e necessidades de geração de caixa possibilitando investigar as transações que afetaram o caixa durante determinado período. Com base nesses indicadores observou-se que a empresa possui capacidade de honrar seus compromissos financeiros.

A empresa elabora o fluxo de caixa pelo método direto de acordo com o modelo sugerido pelo Comitê de Pronunciamentos Contábeis (CPC) no sentido geral, sendo apresentado, de forma mais resumida, situando todas as contas de forma sintética, representando o que efetivamente foi realizado no período sob análise.

O fluxo de caixa das atividades operacionais da empresa é de fundamental importância para analisar a capacidade de sobrevivência no mercado, quando positivo, leva a conclusão que a empresa tem potencial para amortizar dívidas, pagar juros e fazer financiamentos. $\mathrm{O}$ fluxo caixa das atividades de investimento demonstram as operações relacionadas às aquisições e alienações de bens imobilizados, o que não ocorre na empresa no período analisado. Por fim, o fluxo de caixa das atividades de financiamento demonstram os empréstimos e financiamentos tomados, incluído os seus respectivos encargos, atividade essa que a empresa não estava utilizando.

Percebe-se, que nesse demonstrativo são apresentados as transações de características financeiras, onde o ponto de partida é o saldo do caixa, contudo, é adicionado aos recursos oriundos dos embolsos e subtraído os desembolsos, resultando assim, no saldo final das disponibilidades imediatas. Portanto, independendo de outras movimentações de natureza econômicas que não alteram diretamente as disponibilidades do caixa.

Os fatos apresentados demonstram a eficiência da utilização do fluxo de caixa pelo método direto como ferramenta gerencial, considerando-o como instrumento de suporte à tomada de decisões, o fluxo de caixa possibilita ao gestor a programação e o acompanhamento das entradas (recebimentos) e as saídas (pagamentos) de recursos financeiros, de forma que a empresa possa operar de acordo com os objetivos e as metas determinadas, a curto prazo, sendo que a curto prazo para gerenciar o seu capital de giro.

Apesar de possuir o fluxo de caixa como ferramenta de controle para a gestão e, na medida em que a mantém atualizado poderá estimar a qualquer momento o volume de entradas e saídas.

\subsection{Apresentação e dados obtidos}


Estudo de caso sobre fluxo de caixa como ferramenta de controle para empresa do setor de cosméticos em Tangará da Serra - MT

Cristiane Sanini

Maykon J.B. de Camargo

Em 2006, surgiu em Tangará da Serra-MT a organização tratada neste estudo como Empresa X, cujo ramo de atividade é o comércio de cosméticos, cabe ressaltar que ela de acordo com a Lei 11638, de 2007, não está obrigada a elaborar a Demonstração de Fluxo de Caixa, pois está enquadrada na tributação do Simples Nacional que é um regime compartilhado de arrecadação, cobrança e fiscalização de tributos aplicável às Microempresas e Empresas de Pequeno Porte,

De acordo com o artigo 79-E da Lei Complementar $n^{\circ}$ 123, de 2006 (alterada pela Lei Complementar $n^{\circ} 139$, de 2011), a empresa de pequeno porte optante pelo Simples Nacional que durante o ano calendário não auferir receita bruta total anual de R \$ 3.600.000,00 (três milhões e seiscentos mil reais), apesar de não estar obrigada a fazer essa demonstração, a empresa elabora pelo método direto de apresentação e faz-se a análise das informações como ferramenta de apoio na gestão do caixa e tomada de decisão.

$\mathrm{O}$ estudo foi realizado em empresa denominada ficticiamente $\mathrm{X}$, preservando sua identidade por conter na pesquisa dados financeiros que podem expor a mesma. Desde a sua fundação e até a data do estudo sem nenhuma alteração contratual tendo a mesma seus números calculados e demonstrados por meio de tabelas e planilhas.

Esta análise evidenciou os resultados obtidos e também os valores apurados em cada mês, com o intuito de verificar a capacidade de geração de caixa pelo método direto. $\mathrm{Na}$ Quadro 2 foram demonstradas as receitas auferidas pela empresa no período de julho a dezembro de 2012 e janeiro a junho de 2013, tendo como única receita operacional a venda dos produtos comercializados pela empresa.

Percebeu-se que no mês de dezembro de 2012 houve aumento nas vendas devido ao Natal, conforme informado pelo gestor da organização, data comemorativa importante para o comércio. As vendas ocorreram devido a empresa atender grande número de salões de beleza no município, ou seja, pessoa jurídica e por possuir variedade significativa de produtos destinados aos profissionais da beleza. Já no mês de maio o aumento nas vendas foi devido ao dia das mães, e ao contrário do mês de dezembro os produtos com maior saída são para clientes pessoa física.

Quadro 02: Demonstrativo da Receita Bruta Total da Empresa Estudada

\begin{tabular}{|c|cc|c|}
\hline Mês Competência & Receita Total & $(\mathbf{R} \$)$ & \% \\
\hline jul/12 & $\mathrm{R} \$$ & $43.123,68$ & 8,41 \\
\hline ago/12 & $\mathrm{R} \$$ & $41.987,55$ & 8,19 \\
\hline set/12 & $\mathrm{R} \$$ & $41.456,78$ & 8,09 \\
\hline out/12 & $\mathrm{R} \$$ & $42.764,12$ & 8,34 \\
\hline
\end{tabular}


Estudo de caso sobre fluxo de caixa como ferramenta de controle para empresa do setor de cosméticos em Tangará da Serra - MT

Cristiane Sanini

Maykon J.B. de Camargo

\begin{tabular}{|c|cc|c|}
\hline nov/12 & $\mathrm{R} \$$ & $43.788,87$ & 8,54 \\
\hline $\mathrm{dez} / 12$ & $\mathrm{R} \$$ & $55.998,61$ & 10,92 \\
\hline $\mathrm{jan} / 13$ & $\mathrm{R} \$$ & $43.652,78$ & 8,52 \\
\hline $\mathrm{fev} / 13$ & $\mathrm{R} \$$ & $35.987,89$ & 7,02 \\
\hline $\mathrm{mar} / 13$ & $\mathrm{R} \$$ & $38.689,90$ & 7,55 \\
\hline $\mathrm{abr} / 13$ & $\mathrm{R} \$$ & $38.354,23$ & 7,48 \\
\hline $\mathrm{mai} / 13$ & $\mathrm{R} \$$ & $46.965,45$ & 9,16 \\
\hline & $\mathrm{R} \$$ & $39.879,65$ & 7,78 \\
\hline Total & & $\mathbf{5 1 2 . 6 4 9 , 5 1}$ & $\mathbf{1 0 0}$ \\
\hline
\end{tabular}

Fonte: Dados da Pesquisa 2013.

Conforme demonstrado no quadro 2, observou-se que a empresa obteve total de R $\$$ $512.649,51$ de receita bruta dos meses de julho de 2012 a junho de 2013, referente a receita bruta obteve-se os valores mensais.

Para a obtenção dos dados foram lançadas, em planilha eletrônica elaborada pela ferramenta do Excel, onde registrou-se todas as entradas referentes a depósitos à vista, créditos de duplicatas a receber, etc. e também as saídas de caixa, como compra à vista de mercadoria para revenda, pagamento das despesas fixas (energia, água, telefone, folha de pagamento, vigilância, propaganda, entre outros). Pode-se identificar a classificação dos produtos comercializados nesses dois meses de maior receita bruta, como se vê na Tabela 02, que representa a comercialização dos produtos que estão elencados da seguinte forma:

Tabala 02: Comercialização dos produtos

\begin{tabular}{|c|c|c|c|}
\hline \multicolumn{4}{|c|}{ COMERCIALIZAÇÃO DOS PRODUTOS } \\
\hline GRUPOS & MERCADORIAS & \multicolumn{2}{|c|}{ MESES } \\
\hline & & DEZEMBRO & MAIO \\
\hline 1 & $\begin{array}{l}\text { Shampoo / Condicionador / Creme de pentear / } \\
\text { Máscara hidratante / Creme de tratamento / } \\
\text { Filtro solar para cabelos / Óleo reparador / Spray fixa - } \\
\text { dor cabelo / Kit hidratação / Ampolas / }\end{array}$ & $\begin{array}{c}\mathrm{R} \$ \\
14.872,19\end{array}$ & $\begin{array}{c}\mathrm{R} \$ \\
12.356,41\end{array}$ \\
\hline 2 & $\begin{array}{l}\text { Esmalte / Acetona / Algodão / lixa de unha / } \\
\text { Alicate de cuticula / Alicate de unha / Removedor } \\
\text { de esmaltes / Palito de unha / Lixa para pés / } \\
\text { Óleo de banana / Adesivos para unhas / Adesivos } \\
\text { Unhas postiças / strass para unhas / Carimbos / }\end{array}$ & $\begin{array}{c}\mathrm{R} \$ \\
8.381,95\end{array}$ & $\begin{array}{c}\mathrm{R} \$ \\
6.387,29\end{array}$ \\
\hline 3 & $\begin{array}{l}\text { Tinturas / Agua Oxigenada / Cremes de Alisamento / } \\
\text { Produtos escova progressiva / Produtos escova defi- } \\
\text { nitiva / Produtos Relaxamento / Produtos para alinha- } \\
\text { mento de fios / Tonalizantes / Produtos escova } \\
\text { inteligente / Tratamento redutor de friz / Permanentes / } \\
\text { / Produtos escova marroquina / Kit cauterização / } \\
\text { Produtos alisamento / Tratamento redutor de volume / }\end{array}$ & $\begin{array}{c}\mathrm{R} \$ \\
21.126,29\end{array}$ & $\begin{array}{c}\mathrm{R} \$ \\
9.829,73\end{array}$ \\
\hline & Luvas descartáveis / Pentes / Escovas / Tocas descar- & $\mathrm{R} \$$ & $\mathrm{R} \$$ \\
\hline
\end{tabular}


Estudo de caso sobre fluxo de caixa como ferramenta de controle para empresa do setor de cosméticos em Tangará da Serra - MT

Cristiane Sanini

Maykon J.B. de Camargo

\begin{tabular}{|c|c|c|c|}
\hline 4 & $\begin{array}{l}\text { táveis / Tocas térmicas / Toalhas para salão / } \\
\text { Secador de cabelo / Pranchas / Babyliss / Mesa para } \\
\text { manicure / Aventais / Tesouras profissionais / } \\
\text { Máquina de corte de cabelo / Máquina de acabamento / } \\
\text { Espelhos / Lavatórios / Cadeira para cortes / Mesa }\end{array}$ & $4.973,87$ & $3.872,80$ \\
\hline 5 & $\begin{array}{l}\text { Batom / Sombra / Lápis de olho / Lápis de boca / } \\
\text { Corretivo / Base / Pó compacto / Spray fixador maqui- } \\
\text { agem / Removedor de maquiagem / Demaquilante / } \\
\text { Lenços umedecidos / Paletas de sombras / Kit de } \\
\text { maquiagem / Estojo de maquiagem 3D / Máscaras }\end{array}$ & $\begin{array}{c}\mathrm{R} \$ \\
3.972,46\end{array}$ & $\begin{array}{c}\mathrm{R} \$ \\
6.892,91\end{array}$ \\
\hline 6 & $\begin{array}{l}\text { Creme corporal / Filtro solar / bloqueador solar / } \\
\text { Baton protetor solar / Hidratante para o Corpo / } \\
\text { Hidratante para os pés / hidratante para as mãos / } \\
\text { Oleo de banho / Espuma para banho / Creme depila- } \\
\text { tório / Produtos limpeza de péle / Creme de barbear / } \\
\text { Desodorante / Colõnias / Perfumes / Cera depilatória / }\end{array}$ & $\begin{array}{c}\mathrm{R} \$ \\
2.671,85\end{array}$ & $\begin{array}{c}\mathrm{R} \$ \\
7.626,31\end{array}$ \\
\hline & TOTAIS & $R \$ 55.998,61$ & $R \$ 46.965,45$ \\
\hline
\end{tabular}

Fonte: Dados da empresa, 2013.

Percebe-se que no mês de dezembro obteve-se a maior receita bruta mensal devido as festividades e, registrado o aumento considerável nas vendas em comparação com outros meses do ano, assim, o comércio tem o mês de dezembro como o melhor período para vendas, e maio ganha destaque para o comércio e é representado o segundo Natal para o segmento, devido a data do dia das mães.

Os produtos comercializados são classificados em grupos distintos, tais como:

Grupo 01: produtos destinados a comercialização de pessoas fisicas para uso doméstico;

Grupo 02: comercializados por pessoas fisicas para uso doméstico e por pessoas jurídicas para uso profissional, ou seja, salões de beleza;

Grupo 03: destinados mais especificamente para uso profissional, mas também é consumido alguns itens desse grupo por pessoas fisicas;

Grupo 04: comercializados na sua grande maioria por salões de beleza, ou seja, pessoa jurídica havendo exceções de comercialização por pessoas físicas;

Grupo 05: comercializados por pessoas fisicas e pessoas juridicas;

Grupo 06: comercializados por pessoas físicas e pessoas jurídicas.

Não há regra geral na vendas dos produtos, quaisquer deles podem ser vendidos tanto para pessoa física quanto para pessoa juridica.

\subsection{Modalidade de Fluxo de Caixa - Método Direto}


Estudo de caso sobre fluxo de caixa como ferramenta de controle para empresa do setor de cosméticos em Tangará da Serra - MT

Cristiane Sanini

Maykon J.B. de Camargo

Seguindo o objetivo do estudo que é a geração de caixa como ferramenta de controle através do fluxo de caixa pelo método direto tem se as informações das atividades operacionais, de investimentos e de financiamentos para demonstrar a situação da empresa, em determinado período essas informações vieram a beneficiar os usuários que estão interessados em conhecer como a entidade gera e utiliza os recursos de caixa, independentemente da natureza das suas atividades.

Nesta modalidade de fluxo de caixa refere-se às transações originadas das atividades operacionais, de investimento e de financiamentos, nesse estudo apresentado pelo método direto que explicita os recebimentos (clientes, juros, dividendos e outros) e os pagamentos (empregados, fornecedores de produtos e serviços, juros, impostos e outros) brutos de dinheiro dos componentes das atividades, mostrado na Tabela 03, que representa o segundo semestre de 2012, baseado no Balanço Patrimonial, nas Demonstração dos Lucros ou Prejuízos Acumulados; na de Resultado do Exercício e na do Fluxo de Caixa, assim os gestores da empresa têem informações formuladas segundo suas necessidades, especificando os pontos mais relevantes.

Tabela 03: Demonstrativo do fluxo de Caixa pelo Método Direto da empresa estudada.

\begin{tabular}{|c|c|c|c|c|c|c|}
\hline \multicolumn{7}{|c|}{ Demonstração do Fluxo de Caixa - Método Direto } \\
\hline Atividades & $\mathrm{jul} / \mathbf{1 2}$ & ago/12 & set/12 & out $/ 12$ & nov/12 & dez/12 \\
\hline \multicolumn{7}{|l|}{ Atividades operacionais } \\
\hline Recebimentos de clientes & $43.123,68$ & $41.987,55$ & $41.456,78$ & $42.764,12$ & $43.788,87$ & $55.998,61$ \\
\hline $\begin{array}{l}\text { Pagamentos a fornecedores e } \\
\text { empregados }\end{array}$ & $-19.325,53$ & $-18.425,10$ & $-19.145,90$ & $-19.020,40$ & $-23.480,12$ & $-24.453,94$ \\
\hline Caixa gerado pelas operações & $23.798,15$ & $23.562,45$ & $22.310,88$ & $23.743,72$ & $20.308,75$ & $31.544,67$ \\
\hline Juros pagos & $-19,87$ & $-16,73$ & $-17,30$ & $-21,19$ & $-12,40$ & $-15,73$ \\
\hline IR e contribuição social pagos & $-1.052,43$ & $-1.144,40$ & $-1.079,45$ & $-1.098,74$ & $-1.097,70$ & $-1.321,10$ \\
\hline $\begin{array}{c}\text { Caixa líq das atividades } \\
\text { operacionais }\end{array}$ & $22.725,85$ & 22.401,32 & 21.214,13 & $22.623,79$ & $19.198,65$ & $30.207,84$ \\
\hline \multicolumn{7}{|l|}{ Atividades de investimento } \\
\hline Juros recebidos & 402,21 & 453,12 & 320,15 & 302,10 & 297,00 & 318,90 \\
\hline $\begin{array}{c}\text { Caixa líq das atividades de } \\
\text { investimento }\end{array}$ & 402,21 & 453,12 & 320,15 & 302,10 & 297,00 & 318,90 \\
\hline \multicolumn{7}{|l|}{ Atividades de financiamento } \\
\hline $\begin{array}{c}\text { Caixa líq das atividades de } \\
\text { financiamento }\end{array}$ & $\mathbf{0 , 0 0}$ & $\mathbf{0 , 0 0}$ & $\mathbf{0 , 0 0}$ & $\mathbf{0 , 0 0}$ & $\mathbf{0 , 0 0}$ & $\mathbf{0 , 0 0}$ \\
\hline Caixa liquido ao fim do período & $23.128,06$ & $22.854,44$ & $21.534,28$ & $22.925,89$ & $19.495,65$ & $30.526,74$ \\
\hline
\end{tabular}

Fonte: Dados da Pesquisa, 2013.

Para Ribeiro (2005, p.304), “[...] pelo método direto os Recursos Derivados das operações são indicados a partir dos recebimentos e pagamentos decorrentes das operações normais efetuados durante o período." 
Estudo de caso sobre fluxo de caixa como ferramenta de controle para empresa do setor de cosméticos em

Tangará da Serra - MT

Cristiane Sanini

Maykon J.B. de Camargo

Destacando algumas informações levantadas através da análise do fluxo de caixa pelo método direto, é percebido que a empresa estudada no mês de dezembro teve o maior caixa líquido do semestre, um total de $\mathrm{R} \$ 30.526,74$, as principais fontes de recursos da organização foram advindas das vendas a vista e recebimentos de clientes que totalizam $\mathrm{R} \$ 55.998,61$. Os índices de todas as contas contidas no fluxo de caixa pelo método direto são calculadas em relação as entradas de caixa, ou seja, são verificadas as receitas.

As saídas de caixa também são calculadas em relação as entradas, dessa maneira são verificadas as contas que demandaram maiores saídas de recursos, que no segundo semestre de 2012 foram as atividades operacionais, ou seja, as contas relacionadas com pagamentos de fornecedores e empregados, totalizando $\mathrm{R} \$ 24.453,94$ lembrando que no mês de dezembro houve o pagamento de comissões e $13^{\circ}$ salários, verificando também, percebeu-se que essas foram as saídas mais onerosas para a organização nesse semestre possibilitando assim exame minucioso e o estudo de maneiras para melhorar a distribuição desses desembolsos.

A primeira medida a ser tomada foi o planejamento das saídas de numerários referentes aos fornecedores e salários, mais especificamente referente aos salários que no mês de dezembro, representavam em torno de $43,67 \%$ das despesas referente a receita bruta, para rescalonar os desembolsos referente aos salários foi optado por efetuar para o próximo exercício o pagamento do $13^{\circ}$ em duas parcelas, sendo a primeira em novembro, e a outra em dezembro.

Para Maximiano (2000, p.11), “o usuário dessa demonstração tem uma visão do planejamento, da tomada de decisão e da capacidade do gestor em lidar com muitas das ações concernentes ao caixa." A Demonstração do Fluxo de Caixa analisada, em conjunto com as demais demonstrações contábeis, gera informações que auxiliam os usuários na avaliação de liquidez, solvência, e capacidade que as empresas possuem em se adaptar às novas circunstâncias e aproveitar as melhores oportunidades de investimento.

É oportuno lembrar que o modelo da demonstração apresentado é ferramenta de apoio ao processo decisório, elaborado com base nas informações do fluxo de caixa realizado, informando-lhes a situação e a capacidade que a empresa teve de geração de caixa num determinado período.

Percebe-se que o fluxo de caixa pelo método direto fornece uma bagagem de informações sobre as entradas e saídas da organização sendo de fácil entendimento para todos os usuários, inclusive quanto à capacidade da entidade de aplicar as sobras e/ou captar recursos junto a terceiros. 
Estudo de caso sobre fluxo de caixa como ferramenta de controle para empresa do setor de cosméticos em Tangará da Serra - MT

Cristiane Sanini

Maykon J.B. de Camargo

Portanto, fica evidenciada a necessidade de se prestar especial atenção ao caixa gerado pelas atividades operacionais, uma vez que ele é o termômetro aferidor do potencial de sucesso da organização, o demonstrativo do fluxo de caixa pelo método direto na empresa, teve o objetivo de informar como comportou-se o fluxo de pagamentos e recebimentos no período.

O fluxo de caixa busca informações no financeiro da entidade. É através dele que a empresa planeja e toma decisões importantes de investimentos, financiamentos, distribuição de recursos, entre outros fundamentais para a continuidade das operações normais do seu negócio. Com isso o fluxo de caixa representa a movimentação financeira das disponibilidades, conforme mostra a Tabela 04.

Tabela 04: Demonstrativo do fluxo de Caixa pelo Método Direto da empresa estudada.

\begin{tabular}{|c|c|c|c|c|c|c|}
\hline \multicolumn{7}{|c|}{ Demonstração do Fluxo de Caixa - Método Direto } \\
\hline Atividades & jan/13 & fev/13 & $\operatorname{mar} / 13$ & abr/13 & mai/13 & jun/13 \\
\hline \multicolumn{7}{|l|}{ Atividades operacionais } \\
\hline $\begin{array}{l}\text { Recebimentos de clientes } \\
\text { Pagamentos a fornecedores e }\end{array}$ & $43.652,78$ & $35.987,89$ & $38.689,90$ & $38.354,23$ & $46.965,45$ & $39.879,65$ \\
\hline empregados & $-17.853,15$ & $-18.746,80$ & $-18.457,42$ & $-18.996,18$ & $-19.201,67$ & $-19.007,52$ \\
\hline Caixa gerado pelas operações & $25.799,63$ & $17.241,09$ & $20.232,48$ & $19.358,05$ & $27.763,78$ & $20.872,13$ \\
\hline Juros pagos & $-14,49$ & $-16,31$ & $-19,72$ & $-18,42$ & $-7,84$ & $-9,04$ \\
\hline IR e contribuição social pagos & $-1.032,42$ & $-1.021,90$ & $-1.085,46$ & $-1.065,43$ & $-1.077,98$ & $-1.083,41$ \\
\hline $\begin{array}{c}\text { Caixa líq das atividades } \\
\text { operacionais }\end{array}$ & 24.752,72 & $16.202,88$ & $19.127,30$ & $18.274,20$ & $26.677,96$ & $19.779,68$ \\
\hline \multicolumn{7}{|l|}{ Atividades de investimento } \\
\hline Juros recebidos & 297,42 & 338,5 & 417,2 & 382 & 373,8 & 355,1 \\
\hline $\begin{array}{c}\text { Caixa líq das atividades de } \\
\text { investimento }\end{array}$ & 297,42 & 338,5 & 417,2 & 382 & 373,8 & 355,1 \\
\hline \multicolumn{7}{|l|}{ Atividades de financiamento } \\
\hline $\begin{array}{l}\text { Caixa líq das atividades de } \\
\text { financiamento }\end{array}$ & $\mathbf{0}$ & $\mathbf{0}$ & $\mathbf{0}$ & $\mathbf{0}$ & $\mathbf{0}$ & $\mathbf{0}$ \\
\hline $\begin{array}{c}\text { Caixa liquido ao fim do } \\
\text { período }\end{array}$ & $25.050,14$ & $16.541,38$ & $19.544,50$ & $18.656,20$ & $27.051,76$ & $20.134,78$ \\
\hline
\end{tabular}

Fonte: Dados da Pesquisa, 2013.

Com relação a utilização de indicadores, pode-se afirmar que uma das formas mais utilizadas para se avaliar o desempenho da empresa é a que se realiza por meio do cálculo, ou seja, o total das entradas menos o total das saídas e da interpretação de índices financeiros (Maximiano, 2000). Para Gitman (2002, p.129),“a análise de índices não é meramente a aplicação de uma fórmula sobre dados financeiros para calcular um dado índice. Mais importante é a interpretação do valor do índice”. Portanto, a interpretação de indicadores 
Estudo de caso sobre fluxo de caixa como ferramenta de controle para empresa do setor de cosméticos em Tangará da Serra - MT

Cristiane Sanini

Maykon J.B. de Camargo

financeiros permite a análise da situação atual da empresa, bem como simular projeções futuras.

Visando investigar a geração de caixa da empresa analisada no primeiro semestre de 2013, analisou-se que no mês de maio houve a maior receita bruta, um total de $\mathrm{R} \$ 46.965 .45$, devido a data comemorativa do dia das mães, que para a empresa é considerado o segundo melhor período do ano para as vendas. No entanto, percebeu-se que a empresa teve desembolso de $\mathrm{R} \$ 19.201,67$ com o pagamento de fornecedores e salários, lembrando que os colaboradores da área de vendas recebem comissões, sendo assim esse desembolso representa 40,89\% da receita bruta mensal, a empresa portanto obteve nesse período receita líquida de $\mathrm{R}$ \$ 27.051,76, com a geração dessas informações de liquidez, solvência, a empresa possui capacidade em adaptar-se e aproveitar as melhores oportunidades de investimento.

As informações obtidas, por meio da demonstração do Fluxo de caixa pelo método direto, indicam que a empresa possui o controle das entradas e saídas de seus recursos financeiros, o que lhe proporciona maior confiança em decisões de investimentos, além disso, possibilita aos gestores avaliação mais acirrada sobre a liquidez da empresa.

\section{CONSIDERAÇÕES FINAIS}

O objetivo principal que se buscou alcançar, neste estudo de caso foi analisar como se dá o uso do método direto do fluxo de caixa na organização analisada e pode-se perceber que para a empresa se manter atualizada e com controle eficaz o uso do Fluxo de Caixa pelo Método direto, torna-se ferramenta de extrema importância para manter a empresa arrumada, pois tendo o controle do método direto do fluxo de caixa a empresa terá êxito nos negócios tendo mais tempo de vida no mercado.

No que diz respeito à análise da utilização da demonstração do fluxo de caixa pelo método direto pela empresa, chegou-se à conclusão de que as informações aferidas servem de grande apoio e suporte decisório para a empresa, o método direto é elaborado mensalmente com base nos recebimentos e pagamentos, gerando informações imediatas e facilitando as devidas correções. Além disso, tem como vantagem permitir a geração de informações com base em critérios livres de qualquer interferência da legislação fiscal.

As análises mensais da demonstração do fluxo de caixa pelo método direto, terão reflexos no curto prazo da organização, gerando uma política financeira cada vez mais bem elaborada e planejada. Além disto, visa também a obtenção de informações importantes, tais como: verificar a capacidade da empresa em gerar os recursos necessários para custear suas 
Estudo de caso sobre fluxo de caixa como ferramenta de controle para empresa do setor de cosméticos em Tangará da Serra - MT

Cristiane Sanini

Maykon J.B. de Camargo

operações; determina o capital em giro no período, sendo forma dinâmica de apresentar o demonstrativo, que pode ser analisado a cada período de apuração do lucro líquido, ou seja, é feito todos os meses já que a empresa apura o lucro líquido mensalmente.

O primeiro objetivo específico, que foi apresentar os aspectos conceituais quanto ao planejamento financeiro, visando o fluxo de caixa pelo método direto foi atingido, pois foi apresentado um embasamento teórico sobre o assunto no capítulo 02 item 2.6 onde fala do fluxo de caixa e 2.6.1 que retrata o método direto. O segundo objetivo específico, que foi analisar o controle do fluxo de caixa pelo método direto também foi atingido, pelo fato da empresa contribuir com informações relevantes para o estudo, através de documentos, tais como: Demonstração do Resultado do Exercício, Livro Diário, Livro Razão, Livro Registro de Entradas, Livro de registro de saídas, Balanço Patrimonial entre outros, onde pode-se analisar esses documentos e apurar os resultados obtidos na demonstração do fluxo de caixa, e o terceiro objetivo específico, que foi demonstrar os resultados do método direto através de planilhas e/ou tabelas e os benefícios que pode trazer para a empresa, esse também foi atingido através das planilhas e tabelas que foram apresentadas, e os benefícios que o método proporcionou para a empresa, como citado no capítulo 02, ítem 2.9 do referencial teórico que relata os benefícios do uso do fluxo de caixa pelo método direto, trazendo visão clara das entradas e saídas, permitindo assim visualização antecipada dos excessos de caixa, criando a possibilidade de simulações que auxiliam na tomada de decisão dos gestores, além de auxiliar em quais períodos a empresa beneficiou-se com saldo de caixa mais elevado.

A pesquisa limitou-se a apenas uma empresa do ramo de cosméticos em Tangará da Serra-MT, visto ser estudo detalhado, também houveram limitações quanto à busca por referências bibliográficas em livros e periódicos nas bibliotecas, pois os acervos encontrados muitos deles estão defasados e sem atualizações recentes a respeito do tema da pesquisa.

Como sugestão para futuras pesquisas recomenda-se elaborar estudo do Fluxo de Caixa pelo método indireto, além de aplicar também a outros seguimentos, como indústrias e prestação de serviços. Outra sugestão é desenvolver pesquisas de campo para verificar se o planejamento financeiro, através do fluxo de caixa, está sendo aplicado nas empresas como, ferramenta de controle gerencial na tomada de decisões para o próximo exercício social.

\section{REFERÊNCIAS BIBLIOGRÁFICAS}


Estudo de caso sobre fluxo de caixa como ferramenta de controle para empresa do setor de cosméticos em

Tangará da Serra - MT

Cristiane Sanini

Maykon J.B. de Camargo

ALMEIDA, Martinho Isnard Ribeiro de. Manual de planejamento estratégico: desenvolvimento de um plano estratégico com a utilização de planilhas Excel. São Paulo: Atlas, 2001.

BERNHOEFT, R. Empresa Familiar: Sucessão Profissionalizada ou Sobrevivência Comprometida. São Paulo: Nobel, 1989.

CPC - Comitê de Pronunciamentos Contábeis. Pronunciamento Técnico 03 Demonstração do Fluxo de Caixa. Disponível em: <http://www.cpc.org.br〉. Acesso em: 26 de outubro de 2013.

CAMPOS FILHO, Ademar. Demonstração dos Fluxos de Caixa.São Paulo: Atlas, 1999.

CERTO, Samuel C.; PETER, J.Paul. Admistração estratégica: planejamento e implantação da estratégica. São Paulo: Makron Books, 1995.

CHERRY, Richard T. Introdução à administração financeira. São Paulo: Atlas,1977.

CHIAVENATO, Idalberto. Administração Financeira. Uma abordagem introdutória. Rio de Janeiro: Ed. Campus, 2006.

DALBELLO, Liliane. A Relevância do uso do Fluxo de Caixa como ferramenta de gestão financeira para avaliação da liquidez e capacidade de financiamento de empresas.

Florianópolis: UFSC, 1999.

DONNELEY, R. A empresa familiar. Revista de Administração de Empresas, v. 7, n. 23, p. 162-198, 1976.

DRUCKER, P. Administrando em Tempos de Grandes Mudanças. São Paulo: Pioneira, 1995.

GIL, Antonio de Loureiro. Sistemas de Informações Contábil/Financeiro. 2.ed. São Paulo: Atlas, 1995.

GITMAN, Lawrence J.. Princípios de Administração Financeira. 7. ed. São Paulo: Harbra, 2002.

GODET, M. A caixa de ferramentas da próspectiva estratégica. Rio de Janeiro: Editora Campus, 1997.

HOJI, Masakazu. Administração Financeira e Orçamentária: matemática financeira aplicada, estratégias financeiras, orçamento empresarial. 8. ed. São Paulo: Atlas, 2010.

IUDÍCIBUS, Sérgio de. Teoria da contabilidade. $7^{\text {a }}$ ed. São Paulo. Atlas, 2010.

KASSAI, Sílvia. As empresas de pequeno porte e a contabilidade. Caderno de Estudos, São Paulo, 1997.

Lei geral das micro e pequenas empresas (n 123/06). São Paulo: Atlas, 2012. 
LEONE, N. A sucessão não é tabu para os dirigentes da PME. In: Encontro da Anpad, 1991, Belo Horizonte. Anais.... Belo Horizonte, set. 1991, p 243-247.

LODI, J.B.Sucessão e Conflito na Empresa Familiar. São Paulo: Pioneira, 1998.

MARION, José Carlos. Contabilidade empresarial. 10 ed. São Paulo; Atlas, 2003. MAXIMIANO, Antonio Cesar Amaru. Introdução à administração. 5. ed. São Paulo: Atlas, 2000.

OLIVEIRA, Djalma de Pinho Rebouças de. Planejamento Estratégico: Conceitos, Metodologias e Práticas. São Paulo: Atlas 1993.

RAUPP, F. M.; BEUREN, I. M. Metodologia da Pesquisa Aplicável às Ciências Sociais. Como elaborar trabalhos monográficos em contabilidade: teoria e prática. 3. ed. São Paulo: Atlas, 2009.

RIBEIRO, Osni Moura. Contabilidade intermediária. São Paulo: Saraiva, 2005.

RICCA, D. Da empresa familiar à empresa profissional. São Paulo: Cultural, 1998.

ROESCH, S. M. A. Projetos de pesquisa:guia para estágios, trabalhos de conclusão, dissertações e estudo de caso. $3^{\mathrm{a}}$ ed. São Paulo: Atlas, 2005.

STONER, J. A. F; FREEMAN, R. E. Administração. Rio de Janeiro. Prentice Hall do Brasil, 1995.

SILVA, E.C; Como administrar o fluxo de caixa das empresas: São Paulo, Atlas, 2005.

TELÒ, Admir Roque. Desempenho Organizacional: planejamento financeiro em empresas familiares. Curitiba: Atlas, 2001.

VERGARA, Sylvia Constant. Projetos e relatórios de pesquisa. São Paulo: Atlas, 2006.

ZDANOWICZ, José Eduardo. Fluxo de caixa: uma decisão de planejamento e controle financeiros. 3. ed. Porto Alegre: D.C. Luzzatto, 1989. 